\title{
ENCRUZILHADAS TEÓRICAS: DESVIOS NECESSÁRIOS NA FORMAÇÃO INICIAL DOCENTE
}

Lilliane Miranda Freitas*

RESUMO: Este texto trata-se de uma pesquisa narrativa, no qual faço discussões no âmbito do currículo a partir da perspectiva pós-crítica. Abordo três eixos temáticos nos quais questiono sobre as produções discursivas que me subjetivaram em meu percurso escolar e formação inicial docente. Discuto no primeiro eixo as noções de diversidade e diferença como necessárias para a compreensão da constituição da identidade. No segundo instante, analiso a constituição da professoralidade através das narrativas fílmicas e como estas atuam na produção de marcas na subjetividade. E por fim, analiso a história do currículo escolar na formação das disciplinas acadêmicas, em especial da Biologia, e como a historização do currículo é importante na compreensão do caráter construído das práticas sociais e de subjetividades.

Palavras-chave: Currículo; Identidade; Formação de Professores.

\section{THEORETICAL CROSSROADS:}

\section{DIVERSIONS NECESSARY IN INITIAL TEACHER EDUCATION}

ABSTRACT: This text is a narrative research, in which I discuss the curriculum from the post-critical perspective. It addresses three themes on which I question the discursive productions that subjectivate me in my educational background and initial teaching formation. The first axis discusses the concepts of diversity and difference, as necessary for understanding the formation of identity. In the second instance, I analyze the establishment of teachingness through the film narratives and how they work to produce brands in subjectivity. And finally, I analyze the history of the school curriculum in the training of academic disciplines, particularly Biology, and how the historicity of the curriculum is important to understand the constructed nature of social practices and subjectivities.

Keywords: Curriculum; Identity; Teacher Training.

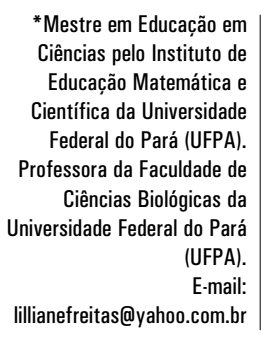

*Mestre em Educação em Ciências pelo Instituto de Educação Matemática e Federa da Universidade (UFPA) fessora da Faculdade de Ciências Biológicas da (UFPA).

E-mail:

lillianefreitas@yahoo.com.br 


\section{INTRODUÇÃO}

Ao ingressar na Pós-Graduação em Educação em Ciências, criei grandes expectativas em relação às disciplinas, às leituras e às discussões que ali seriam feitas. Estava ávida por conhecer melhor a área de Educação, ler textos que mexessem comigo, que me fizessem deslocar, olhar por outro ângulo e com outros óculos a Ciência, os elementos da Educação, os sujeitos da Educação, para mim mesma e para o outro. Isso por que ao longo do curso de Graduação em Licenciatura em Biologia mal tive oportunidade, apesar de ser um curso de Licenciatura, de ler referências e conhecer a área de Educação. Éramos impelidos, desde o início do curso, por toda a estrutura que o coordena e pelos discursos e concepções que ali circulam, a tomarmos caminho somente pela pesquisa pura na área biológica, isto é, tínhamos uma formação totalmente voltada para atuar em laboratórios.

Ao longo das disciplinas no Mestrado, especialmente a disciplina Ciência e Currículo ${ }^{1}$, a qual discute sobre a natureza do currículo para além do que supunham suas teorias tradicionais e abordando-o não somente como uma ferramenta pedagógica que especifique objetivos, metodologias e conteúdos escolares mas, sobretudo, como uma questão de identidade. Assim, os conhecimentos que constituem o currículo não são apenas seleções do repertório cultural da humanidade, são, antes, um conjunto articulado e normatizado de saberes, estabelecidos em arenas de luta, em relações de poder nas quais se elegem e transmitem narrativas e significados cuja função é ensinar formas de ver e ser. Dessa forma, os saberes que formam o currículo estão inextricavelmente envolvidos naquilo que somos e nos tornamos, na nossa identidade, nossa subjetividade (SILVA, 1999).

A partir dessas compreensões, das diversas leituras nessa perspectiva, e diante de novas/outras possibilidades teóricas, comecei a ver essas teorizações como atraentes e potentes ferramentas de análise, discussão e reflexão, uma vez que me provocavam pensar de outra maneira. Sentia-me cada vez mais incomodada e desestabilizada em relação aos significados que atribuía aos sujeitos da Educação e tanto mais desejosa de envolver-me com aquelas discussões. Nesse sentido, passei por angústias epistemológicas e, como diria Corazza (2002), me vi dentro de labirintos por causa da insatisfação com o já-sabido e, neste processo ,sofri alguns deslocamentos por buscar outras significações que questionassem sobre as relações entre poder/saber e subjetividade.

Foi nessa busca por novas significações que senti o desejo de narrar o já vivido, pois o exercício narrativo possibilita rever meu processo de formação, favorecendo a capacidade de reflexão, identificação e relação com o conhecimento, consigo e com o outro. Segundo Catani et al (1998, p. 44), as narrativas sobre si mobilizam "reflexão sobre as formas pelas quais as individualidades se articulam às dimensões mais amplas da vida”, ou seja , possibilitam ao sujeito articular as experiências por quais passaram, dotando-as de significado, identifi- 
cando escolhas, modos de ser e agir que lhe foram impostos, bem como reconhecer-se como sujeito de sua própria formação. Nessa perspectiva, por meio da reflexão das experiências formadoras, o sujeito pode descobrir os significados que tem atribuído aos fatos que viveu e, ao mesmo passo, reconstruir a compreensão que tem de si mesmo (CUNHA, 1997). A partir disso e tomando como referência o caráter reconstrutivo e seletivo da memória (ABRAHÃO, 2008; CUNHA, 1997), escolhi, para elaborar e analisar nesta pesquisa narrativa algumas recordações-referências, denominadas assim por Josso (2004), como elementos simbólicos que decorrem de percepções e imagens sociais, envolvidas em emoções, sentimentos, sentidos e valores que constituíram uma experiência formativa.

Partindo destes entendimentos, vou deter-me neste texto em três desvios $^{2}$ teóricos que realizei e que, apesar de não terem sido os únicos, foram bastante significativos no meu percurso formativo como docente. Esse processo de desvio, de desestabilização, ocorreu ao compreender que os discursos não são simplesmente um entrecruzamento de coisas e palavras, eles fazem mais do que apenas designar coisas e, segundo Foucault (2008, p. 55), “é esse 'mais' que é preciso fazer aparecer e que é preciso descrever". O discurso define um domínio de objetos, uma realidade, ele produz os objetos de que fala, isto é, ele não descreve uma suposta realidade, ele a produz. Dessa forma, o discurso modela práticas sociais, pois toda prática social tem seu caráter discursivo.

Portanto, nessa perspectiva, não há uma única forma verdadeira, fixa e definida de realidade e sujeito, mas sim formas em constante fluxo, indefinidas, instáveis e descentradas, do mesmo modo como a própria linguagem é encarada. Desse modo, a perspectiva pós-crítica ao teorizar o currículo parte da noção de poder-saber, na qual todo saber/conhecimento torna-se igualmente suspeito de vínculo com poder (SILVA, 1994). Assim "sua questão central seria, pois, não tanto 'o quê?', mas 'por quê?"' na análise das conexões entre saber, identidade e poder, pois "nenhuma teoria é neutra, mas está, inevitavelmente, implicada em relações de poder” (SILVA, 1999, p. 16).

\section{$1^{\circ}$ DESVIO: entre a diversidade e a diferença}

Minhas experiências formativas tiveram início antes mesmo de estar envolvida no espaço acadêmico, ainda no espaço familiar. Em minha família a diferença é muito marcante. Em casa somos três irmãos (um homem e duas mulheres), e somos muito diferentes fisicamente, de modo que várias vezes tivemos que mostrar nossos documentos de identidade para acreditarem em nosso parentesco. Passávamos constantemente por situações engraçadas e também, por vezes, embaraçosas e constrangedoras. Já fomos confundidos, eu e minha irmã, como namoradas de meu irmão, nós três como melhores amigos, primos e, até mesmo, eu minha irmã como um casal homossexual. Ouvíamos as pessoas 
falarem com espanto e até com desconfiança de nossas diferenças. Lembro de minha mãe em várias ocasiões estender a mão com os dedos abertos e perguntar: "São iguais? (os dedos) Então, vocês também não precisam ser iguais, são diferentes e pronto."

A partir dessas vivências, havia construído uma idéia fundamentada em uma visão essencialista, universalista, naturalizada de sujeito, na qual as diferenças simplesmente existem porque foram dadas a priori. Entendia que as diferenças existentes faziam parte de uma diversidade inata, que era algo com que já nascíamos tal como explica Silva (2000, p. 73) "na perspectiva da diversidade, a diferença e a identidade tendem a ser naturalizadas, cristalizadas, essencializadas. São tomadas como dados ou fatos da vida social diante dos quais se deve tomar posição". Essa visão essencialista da diferença me levava a compreender que, pelo fato de serem naturais, portanto sem possibilidade de escolha, tinham que ser aceitas e respeitadas para uma convivência justa e pacífica entre os diferentes.

Acreditava que somente através da aceitação pacífica das diferenças, do respeito, é que poderíamos fazer avançar um comportamento baseado na tolerância e na solidariedade. Entendia que era necessário o indivíduo conhecerse, enxergar aquilo que constituía sua identidade e, da mesma, forma tentar compreender o outro. E que isto, a aceitação pacífica da diversidade, por si só, automaticamente, resolveria todos os males de conflitos e injustiças sociais, sendo ela mesma capaz de nos levar a igualdade entre todos.

Meu discurso naquele momento estava atrelado a uma perspectiva que tanto minimiza a força das restrições estruturais ao instituir subjetividades, quanto sugere a aceitação das normas e valores dos grupos privilegiados. Senti-me iludida em imaginar uma sociedade isenta de competição e relações de poder. Passei então a rejeitar, como menciona Moreira (1999, p. 86), "a expectativa de construção de um campo cultural harmônico no qual as diferenças coexistam sem problemas. [Rejeitar] a hipótese de entender a diferença como resultado de fácil negociação entre grupos culturalmente diversos".

Passei então a perceber que identidade e diferença são elementos que não podem ser compreendidos fora de um processo de produção simbólica e discursiva e, dessa forma, não existem previamente à linguagem, como algo natural ou fixo, são histórica e socialmente construídas. E mais, identidade e diferença estão sujeitas a vetores de força, portanto não convivem harmoniosamente, pois sendo uma relação social, estão dependentes de disputas, enredadas em relações de poder, e que estas concorrem por recursos materiais e simbólicos da sociedade (SILVA, 2000).

Nessa perspectiva, aquilo que eu tanto buscava, inicialmente, uma Educação que tivesse em vista o respeito, apesar da aparente nobreza, passou a me parecer bastante ingênua. Ao dizer isso, quero enfatizar que a perda de minha inocência caminha, segundo Costa (2005, p. 41), no sentido de reconhecer a existência de um jogo de correlação de forças que estabelecem critérios de validade 
e legitimidade ao instituir verdades. Essas relações engendram identidades e levam a efeito classificações, dicotomias na cultura e a efeitos materiais sentidos, muitas vezes, através do preconceito, discriminação e desvalorização dos grupos socialmente excluídos.

Assim, considero que entender a identidade como um produto, ou seja, algo construído, fabricado, possibilita-nos pensar em sua desconstrução, reinvenção, não de forma pacífica e não livre de lutas. A maneira como nos olhamos, como dizemos que somos, o que pensamos de nós, tudo é produto, é fabricação, é discurso. Assim, muito mais que respeitar as diferenças, é necessário entender como elas são produzidas no campo social. Entendo agora, contudo, que não é suficiente usar uma estratégia, como diria Silva (2000, p. 98), "terapêutica" que busca tratar os sentimentos de discriminação e preconceito, achando ser isso um desvio de conduta, com atividades de conscientização, que geralmente consistem em apresentar aos estudantes uma visão superficial e distante das diferentes culturas, o que acaba por reforçar o tratamento do outro como exótico. Para isso, é indispensável discutir identidade e diferença como questões políticas em que os mecanismos e sistemas envolvidos na produção e fixação da identidade sejam problematizados.

Ao fazer esse questionamento, da produção da identidade, é imprescindível problematizar as classificações. Nesse sentido, classificar, segundo Silva (2000, p. 82) é "um ato de significação pelo qual dividimos e ordenamos o mundo social em grupos, em classes”. Há, com isso, uma disputa social para quem terá o privilégio de classificar, pois é uma vantagem uma vez que são agregados valores aos grupos classificados. Uma das maneiras de atribuir valor positivo e privilegiar sempre um grupo em relação aos demais seria através dos binarismos do tipo: banco/negro, heterossexual/homossexual. A partir daí, segundo Larrosa (2002), o critério que julga e que valoriza positiva ou negativamente a diferença é o normal, tomado então, como critério normativo de julgamento.

Nesse sentido, normalizar seria eleger uma identidade específica, de modo arbitrário, como padrão em relação ao qual todas as outras serão avaliadas e hierarquizadas. Este é o processo mais sutil da forma como o poder se manifesta na relação de produção de diferença e identidade. O poder que a identidade normal carrega é tão forte que ela é sinalizada como a identidade e todas as demais identidades serão diferentes, ou ainda, anormais (SILVA, 2000). Dessa forma, as identidades só adquirem sentido por meio da linguagem e dos sistemas simbólicos que as representam. Assim, segundo Woodward (2000, p. 10), "a construção da identidade é tanto simbólica quanto social. A luta para afirmar as diferentes identidades tem causas e consequências materiais".

A partir desses entendimentos, comecei a suspeitar do meu modo de ver a Biologia/Ciência, de forma neutra, que apenas descrevia a diversidade existente entre os seres vivos, especialmente a descrição dos seres humanos. Comecei a desconfiar dos discursos biológicos circulantes como discursos verdadeiros, "cientificamente provados", que naturalizam diferenças e encobrem o 
processo de subjetivação. Passei a ver a Ciência como um campo discursivo, que tem exercido papel fundamental na construção conceitual de diferenças e na fixação de identidades sociais. Passei a considerar que, longe de ser um corpo de conhecimento neutro e desinteressado, a Ciência é atravessada por questões de poder por ser produtora de discursos (WILLINSKY, 2004). Assim, a Ciência, como qualquer outra atividade cultural, está envolvida em relações de poder e essas relações devem ser entendidas como pertinentes às relações culturais e sociais, por isso, importa conhecê-las, questioná-las, desmontá-las, modificá-las

Neste processo de fixação da identidade, o discurso biológico-científico tem sido usado como uma ferramenta de naturalização e manutenção de determinadas identidades, tornando-as normais. O discurso biológico essencializa as diferenças, como características naturais ou biológicas, e que são estas características que produzem a diferença assim como, identidade. Mas, as classificações biológicas são, antes de qualquer coisa, discursos, interpretações, e não somente descrições de uma suposta realidade, são significações produzidas histórica e culturalmente, pela linguagem, sem a qual aquilo que é denominado por ela não existe, não possui significado (SILVA, 2000).

Não se trata de negar a materialidade dos objetos estudados pela Biologia e nem, tampouco, de recusar o conhecimento gerado pela Ciência, mas de problematizar suas interpretações como discursos que são contingentes e de dar visibilidade ao caráter material do conhecimento científico, das mediações culturais, econômicas e éticas que ocorrem nas relações entre ciência e sociedade. A relevância de tornar os discursos biológicos alvo de questionamento está em que as descrições científicas naturalizam características, produzindo discursivamente diferenças, assim como identidades. A naturalização de identidades através de "verdades" biológicas é uma das formas pelas quais as reivindicações essencialistas podem fundamentar identidades como fixas e imutáveis (WOODWARD, 2000).

Portanto, considero que importa tomarmos o discurso biológico/científico e outros discursos como construções sociais, históricas e culturais, para assim questionarmos e desconfiarmos daquilo que é repetidamente anunciado como natural, verdadeiro, legítimo e aceitável. Suspeitarmos das representações que a mídia nos apresenta como "naturais", "verdadeiras" ou mais adequadas para vivenciarmos nossas subjetividades, e que por seu poder de legitimação, se tornam hegemônicas. Importa reconhecer nessas instâncias a existência de um jogo de relações de forças que estabelece critérios de validade e legitimidade ao instituir verdades que engessam, que fixam os modos de ser e ver, que estabilizam nossas subjetividades. 


\section{$2^{\circ}$ DESVIO: entre a fixidez e a reinvenção de professoralidades}

Eu gostava/gosto muito de assistir filmes sobre professores, suas lutas em resgatar os alunos mais problemáticos, ou uma escola falida. Admirava como eram abnegados, decididos, fortes e de um nobre caráter. Aqueles filmes me motivavam, me faziam vibrar com suas cenas dramáticas e heróicas do professor em relação aos seus alunos e a escola. A partir daquelas cenas ia significando o que é ser um bom professor e, como argumenta Chaves (2008, p. 11), estava sendo ensinada a olhar, estava tendo meu olhar educado através desses aparatos pedagógicos, as narrativas fílmicas, sobre quem é o bom professor.

Lembro-me que, ao optar pela Licenciatura, meu objetivo era o de poder ajudar às pessoas, aos meus alunos, principalmente àqueles tidos como mais difíceis e marginalizados, no sentido de torná-los cidadãos críticos e esclarecidos, transformá-los em pessoas de sucesso, tornando-os indivíduos melhores e, assim, construir um mundo melhor. Recordo que no curso de Graduação tive um professor que problematizava a questão da identidade de professores representada pela mídia, não só pelos filmes, mas também por propagandas do governo. Mas eu me questionava: que mal havia em ser um professor daqueles? Não são aqueles mesmos os bons professores, capazes de dar a vida pela escola e por seus alunos? Depois de uma aula com este assunto, na qual usamos metáforas da ovelha e do pastor para fazer referência ao aluno e ao professor, respectivamente, escrevi com muita angústia e indignação o seguinte diário:

Eu não queria acreditar, nem tampouco concordar com o que estava sendo dito, pois via a cada argumentação, os meus planos em trabalhar justamente com os alunos mais problemáticos, ficarem cada vez mais distantes e até impossíveis de serem feitos (...). Pensava comigo mesma: a verdadeira Educação que pode gerar liberdade e autonomia do pensamento, mudança no indivíduo e no grupo social é uma utopia que nasceu na cabeça de loucos sonhadores? A luta por esta Educação é uma luta vã, solitária e com derrota certa frente ao sistema que cruelmente a esmaga? Não existe esperança? Devemos nos conformar com a derrota ao ver a vitória como algo impossível e, então, nos tornar uma peça desta máquina destruidora que é o sistema? Fiquei sem respostas. Ao mesmo tempo que fiquei frustrada, tive ainda mais entusiasmo, soprei a pequena brasa que ainda ardia de esperança e tive mais vontade de me armar para a batalha e assim como nos filmes de guerra, quero morrer lutando, não só pelas ovelhas boas, mas também para, ao menos, tentar buscar as perdidas, porque eu entendo que elas não se perderam porque quiseram se perder, desviaram-se do aprisco, mas, sim, porque perderam o caminho de vista, perderam seus sonhos e esperanças, foram deixadas para trás pelo bando e, principalmente, pelo seu pastor, não voltam não porque não querem, mas porque não sabem como voltar (grifos do professor da disciplina. Diário da disciplina Docência do Ensino Fundamental em 25 de abril de 2007).

Não entendia, naquela ocasião, porque ele grifara aquelas palavras em meu diário: armar, batalha, filmes de guerra e morrer lutando. Me me incomodava muito olhar de outra forma ou criticar aquela representação tão naturalizada de bom professor que eu tanto admirava e até buscava ser. Entretanto, apesar de eu pronunciar aquele 
discurso, compreendi, mais tarde, que ele não era meu, eu apenas o reproduzia, fazia circular aquele discurso no cotidiano, em minhas práticas, mas sem minha autoria, no sentido de sua origem e unidade de significações (FOUCAULT, 2006).

A professoralidade, de acordo com Pereira et al (2006), é uma marca produzida no sujeito, na superfície de sua subjetividade que interfere nas suas formas de vir-a-ser. A naturalização das representações de professoralidades, segundo Wortmann (2002), impede que elas sejam compreendidas dentro de um processo de construção cultural e, ao deixar de ser questionada, ganha status de verdade. Por isso é importante, de acordo com Chaves (2008), que as narrativas fílmicas tematizem e questionem os lugares institucionalizados de professor, aluno, escola, conhecimento e poder na sociedade, pois a produção midiática é um dispositivo pedagógico que atua na fixação de papéis sociais para os sujeitos.

As narrativas fílmicas são consideradas aqui como pedagogias culturais pois, ao nos transmitir uma variedade de formas de conhecimento, produzem também valores e saberes que vão naturalizando significados e que acabam por arranjar nossa vida cotidiana, sendo vitais na formação da subjetividade, já que regulam condutas e constroem verdades através de múltiplas estratégias constituídas em certas relações de poder (SILVA, 1999).

Partindo desses entendimentos, torna-se importante reconhecer o papel que as pedagogias culturais da mídia têm na moldagem de identidades sociais e analisar como as representações são construídas e assumidas, ensinadas e aprendidas, mediadas e apropriadas no contexto de formações discursivas e institucionais particulares de poder (GIROUX, 1995). Nessa direção, é pertinente, segundo Fischer (2007), ao tomarmos materiais midiáticos descrever a trama estabelecida pelas complexas relações das verdades que são veiculadas e reafirmadas, a materialidade dos efeitos dessas verdades, as lutas em jogo e os modos de sujeição e subjetivação que elas produzem.

Talvez minha vontade de ser professora tenha muito a ver com aquelas representações dos filmes hollywoodianos do bom professor. Segundo Dalton (1996), o que caracteriza o professor hollywoodiano como bom é por que ele:

Envolve-se com os/as estudantes num nível pessoal, aprende com eles/as e usualmente não se dá bem com os/as administradores/as. Algumas vezes esses "bons" professores ou "boas" professoras tem agudo senso de humor. Eles/elas também frequentemente personalizam o currículo para atender às necessidade cotidianas das vidas de seus/suas estudantes (DALTON, 1996, p. 102).

Ao analisar a literatura infanto-juvenil, Wortmann (2002) também descreve o perfil dos bons professores de Ciências, em que eles aparecem como:

Éticos, preocupados com o bem comum, confiáveis, tolerantes e respeitam os outros; são pobres, mas desprendidos e abnegados, E essas são qualidades que os fazem admirados por seus discípulos e que os habilitam a serem chamados para lidar ou para auxiliar seus alunos (WORTMANN, 2002, p. 39). 
Em pesquisa realizada por Mesquita (2004) na qual ela analisa várias identidades de professores de Matemática produzidas pelos filmes hollywoodianos, encontrei uma que retratava muito bem o perfil com o qual eu me identificava nos filmes que via: o professor como o "salvador do futuro de seus alunos". Esta identificação com a narrativa fílmica, segundo Woodward (2000, p. 18) "é uma forte ativação de desejos inconscientes relativamente a pessoas ou a imagens, fazendo com que seja possível nos vermos na imagem ou na personagem apresentada" ou, ainda, como assinala Chaves (2008), são compulsões e atrações que nos movem.

A característica de "salvador dos alunos" está associada ao perfil do bom professor hollywoodiano porque, na maioria das vezes, esse atributo está relacionado com a demasiada preocupação desses professores por seus alunos, com o estreitamento de amizade e intimidade estabelecidas e, frequentemente, com uma reviravolta que acontece na busca pelos mais "difíceis". Tudo isso, geralmente, vem acompanhado pela indiferença e resistência dos demais colegas e da direção da escola e, aind, a com grande custo pessoal para os salvacionistas. Essas características constituiriam, nos filmes, a medida de sucesso do professor (DALTON, 1996). E este sucesso profissional concede a ele, inclusive, uma outra denominação: educador - não mais professor - pois "do professor é esperado que ele repasse os conteúdos disciplinares, mas do educador se espera muito mais. Espera-se que ele não desista diante dos obstáculos sob pena de jamais se tornar um bom profissional" (CHAVES, 2008, p. 7).

Os filmes, segundo Mesquita (2004), são artefatos culturais nos quais há repetições das narrativas, dos discursos dos modos de ser, neste caso, os modos de ser professor, que produzem os efeitos que o discurso nomeia, ou seja, promove práticas individualizantes, convenciona modos de ser e cristaliza modos e comportamentos professorais, "produzindo perfis-padrão para serem engendrados pela subjetividade de cada um de nós" (MESQUITA, 2004, p. 7). Esses perfis-padrão, de acordo com Wortmann (2002), vão sendo difundidos e naturalizados no intuito de construir uma identidade social desse sujeito, o professor. A tentativa de difundir e de fixar a identidade é deliberada pelas noções essenciais da identidade do trabalhador, seu papel e função social. Ao definir uma referência identitária para os professores, essas narrativas acabam por anular os processos de singularização, bem como negam outras formas de professoralidades (LAWN, 2001).

A adoção aos modos de ser professorais fixos decorre do processo de adaptação às necessidades do mercado de trabalho (MESQUITA, 2004). As alterações na identidade do trabalhador através do discurso são defendidas por Lawn (2001) como manobras do Estado para controlar e gerir mudanças e estabelecer as identidades oficiais, porquanto, "em qualquer período a fixação da identidade do professor, através do discurso, regulamentação e design, é uma forma fundamental de estruturação e reestruturação do trabalho" (LAWN, 2001, p. 118). Além disso, a persistência em investir nos perfis de bom professor atra- 
vés de filmes para inspirar telespectadores é uma maneira de deixar o status quo intacto por meio da manipulação das identidades laborais (DALTON, 1996).

Uma das críticas feitas por Dalton (1996) a esse modelo hollywoodiano de professor é que, apesar de preparar seus alunos para o futuro, envolveremse com eles, esses professores não trabalham ou formam seus estudantes para questionar e mudar as estruturas sociais do mundo, apenas preocupam-se em adaptá-los com sucesso a essas estruturas. No entanto, o que precisamente tornaria os/as professores/as realmente bons/boas, seria questionar o senso comum, deslocar aquilo que é considerado como padrão, quebrar regras/normas que fixam identidades, tornar os alunos políticos e ativistas e atuar em harmonia com eles. Desestabilizar as condições que fixam os modelos, tornando-os contingentes e passíveis a questionamentos e críticas, proporcionará ampliação para as múltiplas possibilidades de ação, convertendo-se em "uma prática que desaloja princípios ordenadores” (POPKEWITZ, 1994, p. 184).

Por isso, é necessário desconfiar das "lentes" que usamos para ver o mundo, através da dúvida, do questionamento aos significados e através da "infidelidade" aos modelos dados a priori, que regulam a invenção para convencionar a homogeneidade do jeito certo de ser professor (CHAVES, 2008; MESQUITA, 2004). Para fugir das cristalizações, urge criar espaços para reinvenção de outras possibilidades de professoralidades, que não serão nem mais verdadeiras nem mais falsas, serão apenas possibilidades de deslocamentos que nos permitam "escapar, ainda que provisoriamente, à captura social da subjetividade" (LARROSA, 1998).

\section{$3^{\circ}$ DESVIO: entre 0 dado e 0 histórico}

Enquanto estudante do Ensino Básico, estudava porque tinha que obter nota e porque a escola determinava, e já que a escola exigia, achava que aqueles conteúdos deveriam mesmo ser importantes mesmo que, para mim, não fosse interessante estudá-los. Passei minha vida estudantil inteira sem me perguntar: por que estudamos e ensinamos determinadas disciplinas e conteúdos nos níveis de Educação? Recordo-me apenas que eu perguntava aos professores de Física e Química, principalmente, para que estudávamos aqueles conteúdos que, para mim, nada tinham a ver com a realidade. Enquanto licencianda, continuava acreditando da mesma maneira, que tudo já estava dado e desinteressadamente posto no currículo acadêmico. Nunca tinha parado para pensar durante a Graduação, como surgiram as disciplinas Ciências e Biologia no currículo e por que eu, como professora, deveria ensinar aqueles conteúdos.

Ao estudar sobre a História do Currículo, pude compreender que não há desinteresse nas lutas e disputas que são travadas para o estabelecimento de uma disciplina escolar e das profissões. Todo o conjunto de documentos que regem de qualquer modo a escolarização "não são 'meramente' linguagens sobre 
Educação" (POPKEWITZ, 1994, p. 208), eles são elementos constituídos em processo de produção. Assim, como já discutido antes, a linguagem é entendida como constituidora das realidades. Esse processo de produção não é produto de uma simples conclusão necessária por aqueles que trabalham nas escolas, mas ocorre em arenas de lutas de saber-poder. Nesse sentido, segundo Goodson (2008), a elaboração do currículo pode ser considerada um processo pelo qual se inventa tradição.

Compreender o currículo não como mero instrumento de transmissão dos saberes acadêmicos tradicionais, mas como constituído por saberes historicamente construídos nos permite questionar "o lugar não contestado" que algumas disciplinas adquiriram no currículo (WORTMANN, 2005, p. 132). A estratégia de historicizar o currículo significaria tomar aquilo que não é problemático, que é tradicional, e analisar por que essas formas de conhecimento são privilegiadas nas relações sociais e em relações de poder. Através da prática de visibilidade e confronto com os sistemas que nos governam é possível interpretar como as práticas sociais e subjetividades são constituídas (POPKEWITZ, 1994). Ao historicizar o currículo, não é suficiente ter claro que o currículo possui uma história, mas segundo Veiga-Neto (2005, p. 96), "a questão principal é: a historicidade do currículo é da sua própria constituição, de modo que não apenas ele tem uma história como ele faz uma história".

Para que uma disciplina passe a fazer parte do currículo, o corpo de conhecimento que a compõe passa por vários estágios nas instituições que podem legitimá-la como tal. Esse processo caracteriza a evolução de uma comunidade acadêmica que busca promover, com objetivos pedagógicos e utilitários, seu conjunto de conhecimentos de modo a defini-lo como uma "disciplina". Esse processo de evolução descrito por Goodson (2008), inicia com o conhecimento sendo primeiramente marginal e de status inferior no currículo. Para legitimá-lo, o primeiro passo é provar que aquele conhecimento é útil de alguma forma, conferindo-lhe um caráter utilitarista.

$\mathrm{Na}$ história do Ensino de Biologia, ainda no século XIX, esta disciplina não possuía um estado de prestígio acadêmico, pois era ensinada como a Ciência das coisas comuns - uma Educação Científica que partia do interesse dos alunos sobre coisas do momento presente. Somente a ampliação das pesquisas e os resultados em diversas áreas do campo da Biologia rendeu-lhe destaque no final do século XIX. No entanto, o ensino de Biologia só veio a despontar como conhecimento importante sob o aspecto utilitário no período entre as duas guerras mundiais e, na década de 1930, alcançou seu lugar no currículo da escola secundária (GOODSON, 2008).

Depois de se tornar disciplina, o conhecimento tem que se manter enquanto conhecimento válido e essa autenticação é feita por meio do rigor do conhecimento, da metodologia e ainda ser passível de exame para conferir vínculo com os especialistas das universidades. No caso da Biologia, após a consolidação como disciplina, o meio para caracterizá-la como "Ciência sólida" foi 
através dos laboratórios, uma versão "diluída de ciência pura, ciência de laboratório, fora aceita como visão correta de Ciências, visão que, em grande parte, persistiu não contestada até os nossos dias" (GOODSON, 2008, p. 26). Possuir esse caráter garantiria a partir de então prestígio, apoios financeiros, recursos, melhores perspectivas de carreira, espaços de poder, etc. Entretanto, esse processo de disciplinarização na mesma proporção que torna o conhecimento mais próximo do rigor acadêmico, o torna mais descontextualizado, abstrato e formal pelos especialistas universitários para os estudantes.

A definição como "disciplina" atua como uma forma de fortalecimento dos elos institucionais entre as comunidades acadêmicas e as organizações burocráticas que definem que tipo de conhecimento é culturalmente válido (GOODSON, 2008). O elo institucional se tornaria mais sólido para os especialistas universitários, se a introdução da disciplina fosse a partir do ensino fundamental para a consolidação de uma área de estudo (WORTMANN, 2005).

Nas escolas, as disciplinas não apenas informam conhecimentos, mas ensinam por meio de seus conteúdos disposições em relação ao mundo e ao "eu", pois a escola regula, justifica e veicula o conhecimento e imprime crenças através dos padrões de seleção, organização, avaliação curricular, ou em qualquer reforma disciplinar. Assim, aprendemos no processo de escolarização tanto informações como maneiras de conhecer, compreender e interpretar:

\begin{abstract}
A escolarização impõe certas definições sobre o que deve ser conhecido. Trata-se da questão spenceriana: Qual conhecimento é mais válido? Certas informações são selecionadas dentre uma vasta gama de possibilidades. Essa seleção molda e modela a forma como os eventos sociais e pessoais são organizados para a reflexão e a prática. Os processos de seleção atuam como "lentes" para definir problemas, através das classificações que são sancionadas. (...) a seleção de conhecimento implica não apenas informação, mas regras e padrões que guiam os indivíduos a produzir seu conhecimento sobre o mundo. Não se trata apenas de que notas são obtidas e diplomas são concedidos. O processo de escolarização incorpora estratégias e tecnologias que dirigem a forma como os estudantes pensam sobre o mundo em geral e sobre o seu eu nesse mundo (POPKEWITZ, 1994, p. 192).
\end{abstract}

\title{
CONSIDERAÇ̃̃ES
}

Estes foram os três grandes desvios que tomei ao longo do meu percurso formativo. A narrativa me serviu como importante instrumento, que me possibilitou deslocar de posições até então enrijecidas e ingênuas. Envolver-me nessas discussões sobre a fabricação identitária e suspeitar da verdade e neutralidade científica/biológica, permitiu-me refletir sobre as relações de poder em que estão imersas nos saberes científicos e curriculares, nos processos pelos quais, eficientemente, instituem posições e condutas sociais e como tacitamente esses papéis são distribuídos e assumidos socialmente produzindo seus efeitos. Faz-se necessário lançar mão desta metodologia de pesquisa junto à professores 
em formação para que estes percebam que há outras possibilidades de ser professor, que não há formas únicas e nem verdadeiras de ser bom professor e mais ainda, fazê-los perceber que se manter no exercício de suspeição, como argumenta Corazza (2002, p. 119), é necessário, pois “exercitar a suspeição sobre a própria formação histórica que nos constituiu e constitui, e interrogá-la sobre se tudo o que dizemos é tudo o que pode ser dito, bem como, se aquilo que vemos é tudo o que se pode ver".

\section{NOTAS}

1 Disciplina optativa do Programa de Pós-Graduação em Educação em Ciências e Matemáticas, ministrada pela professora Dra. Silvia Chaves na Universidade Federal do Pará.

2 Ao referir-me à desvios quero fazer referência aos deslocamentos teóricos que fiz. Aludo estes desvios à estrada teórica que eu tranquilamente trilhava, por ser linear, segura, com partida e chegada certas. Em dados caminhos deparei-me com encruzilhadas que apontavam que outros caminhos eram possíveis além daquele por qual eu vinha percorrendo. Decidi então seguir estes desvios que me conduziram a rumos alternativos, até então desconhecidos para mim

\section{REFERÊNCIAS BIBLIOGRÁFICAS}

ABRAHÃO, M. H. M. B. Metamemória-memórias: memoriais rememorados/ narrados/ refletidos em Seminário de Investigação-Formação. In: PASSEGGI, M. C; BARBOSA, T. M. N. (orgs.) Memórias, memoriais: pesquisa e formação docente. Natal: EDUFRN, 2008, p. 153-178.

CATANI, D. B; SOUSA, C. P; VICENTINI, P. P; SILVA, V. B. O que sei de Mim: narrativas autobiográficas, história da Educação e procedimentos de formação. In: Memórias na Educação. Programa de Pós-Graduação em Educação: Universidade Metodista de São Paulo. v. 1 n. 1. São Bernardo do Campo: UMESP, 1998, p. 31-50.

CHAVES, S. N. Narrativas fílmicas como tecnologias do "eu": deslocamentos e permanências na formação de professores de Biologia. In: Anais do III Congresso Internacional sobre pesquisa (auto) biográfica. Natal, 2008.

CORAZZA, S. M. Labirintos da Pesquisa, diante dos ferrolhos. In: COSTA, M. V. (org). Caminhos Investigativos - novos olhares na pesquisa em Educação. Rio de Janeiro: DP\&A, 2002, p. 105-131.

COSTA, M. V. Currículo e Política Cultural. In: COSTA, M. V. (org.) O currículo nos limiares do contemporâneo. 4 ed. Rio de Janeiro: DP\&A, 2005, p. 37-68.

CUNHA, M. I. Conta-me agora! As narrativas como alternativas pedagógicas na pesquisa e no ensino. Rev. Fac. Educ. São Paulo, v. 23 n. 1-2 , jan./dez. 1997.

DALTON, M. M. O currículo de Hollywood: quem é o "bom" professor, quem á "boa" professora?. Educação e Realidade. Porto Alegre, n. 21 v.1, p. 97-22. 1996.

FISCHER, R. M. B. Mídia, máquinas de imagens e práticas pedagógicas. Revista Brasileira de Educação, v. 12 n. 35, p. 290-299, 2007.

FOUCAULT, M. $A$ ordem do discurso. 13 ed. São Paulo: Edições Loyola, 2006.

FOUCAULT, M. A arqueologia do saber. Rio de Janeiro: Forense Universitária, 2008.

GIROUX, H. A. Memória e pedagogia no maravilhoso mundo da Disney. In: SILVA, T. T. Alienígenas na sala de aula. Rio de Janeiro: Vozes, 1995, p. 97-112.

GOODSON, I. Currículo: teoria e história. 8 ed. Petrópolis: Vozes, 2008.

JOSSO, M. Experiências de vida e formação. São Paulo: Cortez, 2004.

LARROSA, J. Pedagogia profana: danças, piruetas e mascaradas. Porto Alegre: Contra-Bando. 1998.

LARROSA, J. Tecnologias do eu e Educação. In: SILVA, T. T. (org.) O sujeito da Educação: estudos 
foucaultianos. 5 ed. Rio de Janeiro: Vozes, 2002, p. 35-86.

LAWN, M. Os professores e a fabricação de identidades. Curriculo sem fronteiras. n. 2, p. 117-130, 2001.

MESQUITA, C. G. R. O professor de Matemática no cinema: cenários de identidades e diferenças. In: REUNIÃO ANUAL DA ASSOCIAÇÃO NACIONAL DE PÓS-GRADUAÇÃO E PESQUISA EM EDUCAÇÃO, 27., 2004, Caxambu. Anais... Caxambu: ANPED, 2004.

MOREIRA, A. F. B. Multiculturalismo, currículo e formação de professores. In: MOREIRA, A. F. B. (org.). Currículo: Políticas e práticas. Campinas: Papirus, 1999.

PEREIRA, M. V; FAGUNDES, A. D; MORAES, G. R; SILVA, F. S. Influências nos escritos sobre formação de professores. In: OLIVEIRA, V. F. (org.) Narrativas e saberes docentes. Injuí: Editora Unijuí, 2006.

POPKEWITZ, T. S. História do currículo, regulação social e poder. In: SILVA, T. T. (org.) O sujeito da educação: estudos foucaultianos. Petrópolis: Vozes, 1994.

SILVA, T. T. O Adeus às metanarrativas educacionais. In: SILVA, T. T. (org.) O sujeito da Educação: estudos foucaultianos. 5 ed. Rio de Janeiro: Vozes, 1994, p. 247-258.

Documentos de identidade: uma introdução às teorias do currículo. Belo Horizonte: Editora Autêntica, 1999.

. Identidade e diferença: a perspectiva dos estudos culturais. Rio de Janeiro: Vozes. 2000.

VEIGA-NETO, A. Currículo e história: uma conexão radical. In: COSTA, M. V. (org.) O currículo nos limiares do contemporâneo. 4 ed. Rio de Janeiro: DP\&A, 2005.

WILLINSKY, J. Ciência e a origem da raça. In: LOPES, A. C; MACEDO, E. (orgs.). Currículo de Ciências em debate. São Paulo: Papirus, 2004, p. 77-118.

WOODWARD, K. Identidade e diferença: uma introdução teórica e conceitual. In: SILVA, T. T. (org.). Identidade e diferença: a perspectiva dos estudos culturais. Rio de Janeiro: Vozes, 2000, p. 7-72. WORTMANN. M. L. Sujeitos estranhos, distraídos, curiosos, inventivos, mas também éticos, confiáveis, desprendidos e abnegados: professores de Ciências na literatura infanto-juvenil. In: SILVEIRA, R. M. H. (org.) Professoras que as histórias nos contam. Rio de Janeiro: D\&P. 2002, p. 19-46.

- Currículo e Ciências + as especificidades pedagógicas do ensino de Ciências. In:

COSTA, M. V.(org.) O currículo nos limiares do contemporâneo. 4 ed. Rio de Janeiro: DP\&A, 2005, p. 129-157.

Data recebimento: 29/07/2009

Data aprovação: $23 / 06 / 2010$

Data versão final: $14 / 01 / 2011$ 